\begin{tabular}{|l|l|}
\hline Postprint Version & 1.0 \\
\hline Journal website & http://www.sciencedirect.com \\
\hline Pubmed link & \\
\hline DOI &
\end{tabular}

\title{
Communication in health care
}

\author{
P.F.M. VERHAAK, J.M. BENSING, A.M. VAN DULMEN
}

NIVEL, PO Box 1568, 3500 BN Utrecht, The Netherlands

\section{Introduction}

Although communication in health care is as old as Hippocrates, it has only recently received attention in its own right. That is not to say that great doctors such as Hippocrates, Maimonides, Boerhaave or Virchow did not mention the doctor-patient relationship. On the contrary, they stressed that it was of the utmost importance. In fact, in the days before bacteriological and virological knowledge, trust, confidence and the power of persuasion were a doctors most effective tools. But it is only in the last half century that doctor-patient communication has become an object of attention in its own right. The conference on Communication in Health Care, with the abstracts presented in this volume, represents the state of the art in this subject in 1998. In this editorial we give a retrospective account of the preceding issues in this ongoing story.

\section{Theoretical foundations}

Several theoretical perspectives fostered the early studies of doctor-patient communication. From a sociological perspective, the concept of 'power' was a central issue. The 'medical model' elaborated by Parsons ${ }^{1}$ and Freidson ${ }^{2}$ defines a hierarchical relationship between doctor and patient. This relationship was criticized by many, including Thomas Szasz, Ivan Illich ${ }^{4}$ and followers of the Frankfurter Schule, to name just a few of the most well-known. In a special way, ethnomethodology ${ }^{5}$ and conversation analysis ${ }^{6}$ elaborated sociological research on communication at a micro-level through paying attention to linguistic aspects. 'Power,' however, remains a significant theme within this tradition. Psychoanalysis and psychotherapy offered a different point of view. Concepts like therapeutic transference and counter-transference inspired Balint ${ }^{7}$ in his work with small groups of general practitioners. His aim was to make doctors aware of the complex interaction between them and their patients, often built up over a life-time partnership. Carl Rogers ${ }^{8}$ and his ideas of a therapeutic relationship based on unconditional positive regard required attention for such concepts as empathy and interest and focused on the importance of non-verbal behaviour. Another theoretical approach which has exercised considerable influence came from the communication sciences. Dividing communication into senders, receivers, media, and messages, this discipline formulated the requirements to be put on the message in particular. The influence of this approach was especially felt in the field of patient instruction, health promotion, and patient education. Watzlawick's ${ }^{9}$ thorough analysis of interaction between people made clear that messages are not simply messages, but can carry different layers of sometimes contradictory meaning. In addition, senders and receivers do not have fixed roles, but constantly take different points of view. A final group of theoretical approaches to be mentioned here came from information theory and has had its influence on medical decision making ${ }^{10}$.These theoretical approaches, formulated between 1940 and 1970, provide the foundations for the purposes of communication in health care as distinguished by Ong and colleagues ${ }^{11}$ : creating a good personal relationship, exchanging in-formation, and making treatment decisions.

\section{Vocational and postgraduate training}

Training and research into patient-provider interactions seem to have developed more or less independently of each other. For centuries, communication skills were taught In medical education implicitly. The clinical method as taught at universities, mostly in a classical master-disciple relationship with its roots in the middle ages, paid little explicit attention to communicative skills. Students learned to take a good anamnesis, following a hypothetico-deductive route to come to a proper diagnosis. 'Good bed-side manners' were considered to be important, but more of an art than a skill. In fact, communication was learned by imitation of the master, not as a discipline of its own. In 
1924 the first textbook on medical interviewing was published ${ }^{12}$. It must have taken another forty years to put the medical interview on the curriculum, at least in the Netherlands. The content of the curriculum was derived from clinical expertise and focused on good case history taking skills and models for special kinds of interactions, like 'breaking bad news'. As the curriculum was frequently taught by psychologists, early medical communication courses were often inspired by Rogerian psychotherapy. Only in the late 1970s did certain specific results of research into doctor-patient communication begin to influence the content of medical vocational training.

\section{Research}

Research started outside the medical faculties and was dominated by social scientists who used the consultation room as a source for their data. About 50 years ago sociologists began studying human interaction in small groups. The work of Bales ${ }^{13}$ was a first methodological target for the first scholars with an interest in doctor-patient communication. This was in the 1960s, when doctor-patient communication became a subject of research. Category systems derived from Bales' dyads were used by Davis ${ }^{14}$, Korsch ${ }^{15}$, Francis ${ }^{16}$ and others. Communication, classified by Bales' categories, could be characterized by the exchange of information and negative or positive affects and also by several combinations of give and take from the side of doctor and patient. Important determinants and outcomes measured were the expectations of doctor and patient, and the satisfaction and compliance of the patient. All the theoretical perspectives mentioned above can be found in these early descriptions. Affective categories conformed with Rogerian concepts, information exchange with communication theory and decision making and the ratio between the utterances of both parties fitted into a conception of doctor-patient relationship as an exchange of power.

\section{An integrative concept}

An important conceptual milestone was provided by Byrne and Long's “'Doctors talking to Patients",17. Byrne and Long introduced the power-shift model. On one end of the continuum was the dominant doctor who exercised his (yes, in those days most doctors were male) authority by asking closed questions, determining the agenda of the consultation, listening very little, and leaving no silences. At the other end stood the patient-centred doctor who asked open questions, determined the agenda together with the patient, listened, and showed empathy. The resulting concept of patientcentred medicine integrates several theoretical points of view: it is expressed in terms of power, it requires a doctor-patient relationship based on mutual respect and confidence, and it relies heavily on a good exchange of information. Patient-centred medicine provides common ground for clinical medicine, training, and research. It has been developed as a clinical method. It became customary, particularly in general practice, to advocate a policy in which somatic, psychological and social issues were considered together in a biopsychosocial approach. More and more importance was attached to the reason (from the patient's point of view) for a visit, as can be seen in the internationally accepted classification for primary care, the ICPC. Patient-centred medicine's origins can be traced back to the 1970s, but it has been elaborated as a clinical method from the 1980s, in particular by McWhinney, Stewart and colleagues ${ }^{18}$.The patient-centred approach has been influential in vocational training (especially for general practice) from the beginning. Patient-centred medicine has been important in research by providing a standard for good communication. Research in doctor-patient communication has focused on the following research topics:

-description of doctor-patient interaction

-assessment of the determinants of doctor-patient interaction

- study of the effects of doctor-patient interaction

The key concepts to describe interaction have been given: patient centredness, affective and instrumental behaviour. A patient centred approach is a prerequisite that stimulates expression of patient's emotional and instrumental needs. Technically, the concepts can be measured in a number of ways. Roter's adaptation of Bales' category system ${ }^{19}$ has been an important development in the quantification of doctor-patient interaction. As the mere categorization of utterances does not allow for in-depth analysis of what is going on, more qualitative approaches derived from methods of conversation analysis have become popular. 'Patient centredness' is a concept that can be distinguished in each approach. 


\section{Developments 1980-1990}

This was the state of affairs around 1980. Since then, many new initiatives have seen the light. Although some of the first videotaped consultations came from paediatricians, the hard core of training and research took place in the faculties of general practice, especially in countries with a welldeveloped GP curriculum, such as the UK and the Netherlands. Much of the training and many of the textbooks were directed at general practice ${ }^{20}$. In the last few decades, many new initiatives in universities and other educational centres have been directed at doctors, nurses and paramedics. In the US, the Task Force on the Medical Interview ${ }^{21}$ has made great efforts to promote the importance of doctor-patient communication. More recently, this has been continued by the Programme in Communication and Medicine. In the UK, postgraduate training in communication is compulsory and in the Netherlands communication training is a regular part of the specialization for GPs, while postgraduate training for some kinds of specialist is being considered. An issue with a status in its own right is patient education. With a strong emphasis on the content of the message, it was first developed in hospitals, often delegated to nurses rather than integrated with the work of the clinician ${ }^{22}$. Gradually, patient education has been integrated with the work of doctors ${ }^{23} 24$ and paramedics ${ }^{25}$. As far as research is concerned, a number of studies have been conducted that demonstrate the possibility of training doctors ${ }^{26}$ and nurses ${ }^{27}$ to change their communication style. Patient characteristics that correlate with provider-patient interaction are social class, gender, and age ${ }^{28}$. Research has demonstrated the beneficial effects of good communication on patient satisfaction, compliance, recall and understanding, and on more general health outcomes ${ }^{29}$. The relationship between good communication and good quality medical care has been established ${ }^{30}$. These developments in education and research cannot be considered apart from the broader social movements of which they form a part, which they influence and by which they have also been influenced. In the last fifty years medical technology has increased enormously. This has complicated medicine and obscured it as well. Communication should fulfil a very important task in this respect from the perspectives of information as well as of negotiation. On the one hand, new technologies present difficult choices and considerations, so that clear and unambiguous information is needed. On the other hand, technology sometimes suggests more hope for recovery than is realistic. Increasing attention for the patient's position has resulted in changing patient attitudes and demands. Patients who forty years ago were literaly (dependent) sufferers have turned into self-confident consumers who expect value for money. On the other hand, modern medicine expects a lot from the patient: compliance, a healthy life style, and self-efficacy. Good communication is critical in these circumstances.

The changed position of the patient is reflected in changed legislation (informed consent, registration of complaints) and this has its impact on the requirements the medical, nursing and paramedical professions impose on themselves. In most professions, postgraduate education is becoming compulsory and communication is a growing part of the educational package. Increasingly, professional standards are being developed and communication is contributing to it.

Of course, developments are not at the same stage in all countries and every profession. At the risk of some over-generalization, we can say that general practitioners in Northwestern Europe and North America have made most progress to date, although a rapid dissemination can be observed over Southern and Eastern Europe and other continents as well as among medical specialists ${ }^{31}$, nurses ${ }^{32}$ and paramedics.

\section{What is the state of affairs in 1998 ?}

In what respects can the developments, sketched above, be observed in the presentations at the Communication in Health Care Conference? Abstracts of all the presentations are printed in this volume $^{1}$. The broad response indicates that interest in communication in health care is extremely lively.

Many of the contributions, divided over several topics, have been on the agenda for a long time. On the patient side there is patient education, patient empowerment, patient centredness. They are characterized by more thorough research methods such as trials, some of a pre-test -post-test character, others with a controlled design. This appears to be a field where the stage of pure description is passed and hypotheses about meaningful interventions, or significant relationships can be tested. The same is also the case for skills training and communication improvement, where the provider's part is at issue. 
Most of the contributions describe controlled trials. This seems to be indicative of the fact that the needs of the trainees are known; now is the time to demonstrate the effects of the training. Many of the other contributions are concerned with special topics. The bad news interview has traditionally been of concern for every clinician. Some of the topics in this section feature the dilemmas around decision making, the involvement of family members, and conversations with cancer patients. This theme illustrates the importance of informed consent. It is also illustrative for researchers who are presumptuous enough to involve themselves in extremely complicated and sometimes threatening medical situations.

Miscommunication can have many causes. Patients might be handicapped, the doctor-patient relationship might be at fault, or people may use inappropriate conversation techniques.

Genetic counselling is relatively new on the doctor and patient agenda. This newness might itself be a source of misunderstanding. It is a topic where all relevant concepts in communication are relevant: decision making, support and empathy, non-directive (patient centred) behaviour. International and inter-cultural comparison provide deeper insights into the validity and generalizability of concepts developed in a mainly Anglo-Saxon society. This research topic becomes increasingly important as each society becomes more multi-cultural and multi-valued.

Special categories of patients, such as children, severely ill patients, mental health care or handicapped patients each pose their own communication problems. These sessions feature many different training methods facilitating interaction with such specific groups. Then there are contributions directed at specific professions: nurses, physiotherapists, gynaecologists, pharmacists, genetic counsellors, radiologists, and health visitors. In many of these contributions tested methods are applied to new fields. Many of these contributions tend to be descriptive in nature.

Some of the contributions have to do with communication in general. Cross-sectional quantitative and qualitative methods are prevalent.

The majority of contributions are in one way or another empirical by nature. For the contributions that can be categorized under the heading 'research', the most conspicuous methods are conversational analysis, cross-sectional analysis, pre-test -post-test designs and (randomized) controlled trials, in that order. A number of contributions can be classified as the development of measurement instruments; an important section is reserved for educational development.

An interesting dilemma is the tension between generalizability on the one side and validity on the other. Quantitative research tends to oversimplify complicated interactions between providers and patients. Many conversational analytical contributions give the impression of excellent descriptions of exactly that one situation. In both cases, the conclusions reached appear to be reproductions of conclusions drawn thirty years ago.

In the case of quantitative research, the most common output measurements are patient satisfaction, anxiety, quality of life, self-efficacy, preferences, and knowledge on the patient's side and conversation skills and patient-centred communication on the provider's side. Again, most of the measurements have been well known since provider-patient communication became a topic of interest.

Conspicuously absent among the submitted papers were themes such as patient's compliance, gender issues, and biological outcome measures such as hypertension, or blood-sugar regulation.

What has changed is the multiplicity of the research area. What started as an analysis of a simple consultation by a general practitioner or paediatrician and a patient with a common complaint has developed into very difficult interactions with terminal patients, children, people speaking foreign languages, patients in hospital, genetic counselling, patients in home care or suffering from depression, with nurses, pharmacists, health visitors and cardiologists as conversation partners. The conclusion might be drawn that the doctor-patient communication research and training agenda has not changed much in principle during the last ten years. An instrumental tradition, focused on information exchange and an affective tradition, based on an unconditional positive regard have been integrated. Patient-centredness appears as an important condition for balancing both approaches in order to tune them to the patients' needs. Empowerment and self-efficacy are keywords here. The impression is given that communication research is at a stage of piecemeal engineering rather than the development of grand theories. The methodologies of the 1970s have become more refined, the questions more detailed, and many research projects aim to provide technical solutions for practical problems. Innovations are looked for more in new fields of application than in new research questions. 
All these developments together have resulted in a fascinating programme of great promise and with challenges for the future.

\section{LITERATURE}

1. Parsons T. The social system. Glencoe III: The free press, 1951

2. Freidson E. Patients' views of medical practice. New York: Russell Sage Foundation, 1961

3. Szasz TS. The myth of mental illness, foundations of a theory of personal conduct. London: Paladin, 1972

4. Illich I. Medical Nemesis, the expropriation of health. London: Calder \& Boyars, 1975

5. Garfinkel H. Studies in ethnomethodology. Englewood Cliffs NY: Prentice-Hall, 1967

6. Atkinson JM, Heritage JC. Structures of social action: studies in conversation analysis. Cambridge: Cambridge university press, 1984

7. Balint M. The doctor, the patient, the illness. London: Pitman Medical Publishing, 1964

8. Rogers CR. Client-centered therapy, Boston: Houghton Miffin, 1951

9. Watzlawick P, Beavin JH, Jackson DD. Pragmatics of human communications. New York: Norton \& Co, 1967

10. Elstein AS, Shulman LS, Sprafka SA. Medical problem solving. An analysis of clinical reasoning. Cambridge Mass.: Harvard University Press, 1978

11. Ong LML, Haes JCJM de, Hoos AM, Lammes FB. Doctor-patient communication: a review of the literature. Social Science \& Medicine 40, 1995, 903-918

12. White KL. The task of Medicine. Dialogue at Wickenburg. Menlo Park Cal: Henry Kaiser Family Foundation, 1988

13. Bales RF. Interaction Process Analysis: a method for the study of small groups. Reading, Mass.: Addison-Wesley, 1950

14. Davis MS.Variations in patients' compliance with doctor's advice: an empirical analysis of patterns of communication. American Journal of Public Health, 58, 1968, 274-288

15. Korsch BM, Negrete VF. Doctor-patient communication. Scientific American, aug. 1972

16. Francis V, Korsch BM, Morris MJ. Gaps in doctor-patient communications. New England Journal of medicine, 280, 1969, 535-540

17. Byrne PS, Long BEL. Doctors talking to patients, London: HMSO, 1972

18. Stewart M, Brown JB, Weston WW, McWhinney IR, McWilliam CL, Freeman TR, Patient-centred medicine. Thousand Oaks Call: SAGE Publications, 1995

19. Roter DL. Patient participation in the patient provider interaction: the effects of patient question asking on the quality of interaction, satisfaction and compliance. Health Education Monographs, 4 , 1977, 281-315

20. Havelock P. (ed). Professional education for general practice. Oxford: Oxford university press, 1995

21. Lipkin M, Putnam SM (eds). The medical interview: clinical care, education and research. New York: Springer, 1995

22. Visser APh. Patient Education: the Dutch style. Patient Education and Counseling, 1996, 28, 7984

23. Grol R, Beurden $\mathrm{W}$ van, Binkhorst $\mathrm{T}$, Toemen $\mathrm{T}$. Patient education in family practice. The consensus reached by patients, doctors and experts. Family Practice 8, 1991, 133-139

24. Verhaak PFM, Bussbach JT van. Patient education in general practice. Patient Education and Counseling 11, 1988, 119-129

25. Sluijs EM, Patient Education in Physical Therapy. Utrecht, NIVEL, 1991

26. Gask L, McGrath G, Goldberg D. Improving the psychiatric skills of established general practitioners: evaluation of a group teaching. Medical Education, 21, 1987, 362-368

27. Faulkner $\mathrm{A}$. The evaluation of training programmes for communication skills in palliative care. Journal of Cancer Care1, 1992, 75-78

28. Hall JA, Roter DL, Katz NR. Meta-analysis of correlates of provider behavior in medical encounters. Medical Care, 26, 1988, 657-675

29. Stewart M, Roter D (eds). Communicating with medical patients. Newbury park Cal: SAGE, 1989

30. Bensing JM. Doctor-patient communication and the quality of care. Utrecht: NIVEL, 1991

31. Dulmen AM van, Verhaak PFM, Bilo HJG. Shifts in doctor-patient communication during a series of out-patient consultations in noninsulin dependent diabetes mellitus. Patient Education and Counseling, 30, 1997, 227-237

32. Caris-Verhallen WMCM, Kerkstra A, Bensing JM. The role of communication in nursing care for elderly people: a review of literature. Journal of Advanced Nursing, 25, 1997, 915-933 